\title{
Annual Drought in California: Association with Monthly Precipitation and Climate Phases*
}

\author{
SHRADDHANAND SHUKLA \\ Department of Geography, University of California, Santa Barbara, Santa Barbara, California
}

ANNE STEINEMANN

Department of Infrastructure Engineering, Melbourne School of Engineering, University of Melbourne, Melbourne, and College of Science, Technology and Engineering, James Cook University, Queensland, Australia, and Scripps Institution of Oceanography, University of California, San Diego, La Jolla, California

SAM F. IACOBELLIS

Scripps Institution of Oceanography, University of California, San Diego, La Jolla, California

\author{
DANIEL R. CAYAN
}

Scripps Institution of Oceanography, University of California, San Diego, and U.S. Geological Survey, La Jolla, California

(Manuscript received 19 June 2015, in final form 31 August 2015)

\begin{abstract}
Annual precipitation in California is more variable than in any other state and is highly influenced by precipitation in winter months. A primary question among stakeholders is whether low precipitation in certain months is a harbinger of annual drought in California. Historical precipitation data from 1895 to 2013 are investigated to identify leading monthly indicators of annual drought in each of the seven climate divisions (CDs) as well as statewide. For this study, drought conditions are defined as monthly/annual (OctoberSeptember) precipitation below the 20 th/30th percentile, and a leading indicator is defined as a monthly drought preceding or during an annual drought that has the strongest association (i.e., joint probability of occurrence) with a statewide annual drought. Monthly precipitation variability and contributions to annual precipitation, along with joint probabilities of drought among the winter months, are first analyzed. Then the probabilities of annual drought and the variability in leading indicators are analyzed according to different climate phases and CDs. This study identified December within a water year as being the leading indicator that is most frequently associated with annual drought statewide (56\%) and in most of the CDs (the highest was $\mathrm{CD} 2$ at $65 \%$ ). Associated with its leading-indicator status, December drought was most frequently associated with drought in other winter months (joint probability $>30 \%$ ). Results from this study can help stakeholders to understand and assess the likelihood of annual drought events given monthly precipitation preceding or early in the water year.
\end{abstract}

\footnotetext{
* Supplemental information related to this paper is available at the Journals Online website: http://dx.doi.org/10.1175/JAMC-D15-0167.s1.
}

Corresponding author address: Shraddhanand Shukla, 4713 Ellison Hall, Dept. of Geography, University of California, Santa Barbara, Santa Barbara, CA 93106.

E-mail: shrad@geog.ucsb.edu

\section{Introduction and background}

Drought is common in California, causing up to billions of dollars of damage in a single drought year and affecting diverse stakeholders throughout the state. Common questions from interviews with Southern California stakeholders include the following: How can we see a drought coming? Is there a "make or break" month for the year's water supply? If we are dry during 

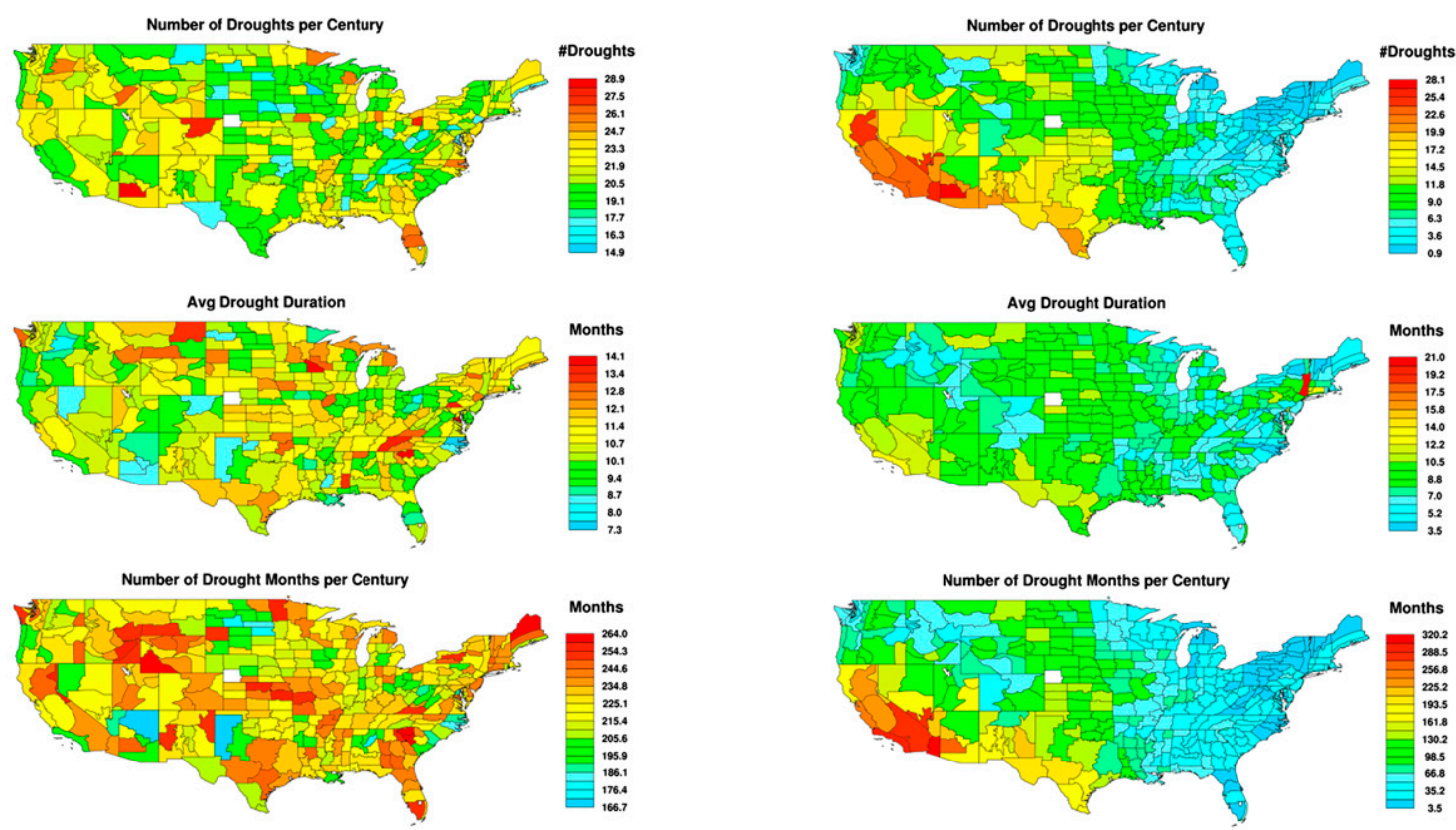

Anomaly Timescale: 12 months

Drought Recovery $>=20 \%$-lle for 3 month

Data File: dhist_t12_po20_pr20_no3_nr3.det

FIG. 1. Frequency of droughts, average drought duration, and number of months in drought per century in all CDs in the CONUS according to drought criteria that are based on a 12-month precipitation anomaly in terms of (a) percentile and (b) percent of normal.

one winter month, is it likely we will be dry for another winter month, and then for the entire water year? (http:// drought.gov/drought/content/california-california-dewspilot; last accessed 5 January 2015). Questions such as these have become even more acute during the last four years of persistent dry conditions in the state (Griffin and Anchukaitis 2014; California Department of Water Resources 2014). Most precipitation in California falls during winter (November-March), making those months critical in determining the occurrence of an annual drought. Past studies have reported the teleconnection of precipitation in California with climate phases such as the Pacific decadal oscillation (PDO; Cayan et al. 1998; Fierro 2014; McAfee 2014), El Niño-Southern Oscillation (ENSO; Cayan et al. 1999; Haston and Michaelsen 1994; Mo and Higgins 1998; Woolhiser et al. 1993), the Madden-Julian oscillation (Jones 2000), and anomalous atmospheric circulations (Cayan and Roads 1984), which contribute to making precipitation highly variable (Dettinger et al. 2011).

Motivated by stakeholder and decision-making needs to understand the variability of precipitation at different temporal and spatial scales across the state, this study investigates historical relationships between monthly and annual precipitation in California, with a focus on drought conditions, for the period of 1895-2013. We address the following questions: 1) Which month was the leading indicator of annual drought in California, and what was the joint probability of occurrence? 2) How was drought occurrence in that month associated with other months? 3) How did the joint probability of annual drought and leading-indicator month vary by climate phase and climate division (CD)?

This study builds upon Steinemann et al. (2015), who analyzed the frequency, duration, and severity of droughts across California, considering characteristics of a drought indicator (precipitation), spatial scale (CD), temporal scale for data (monthly), anomaly averaging period (12 months), percentile threshold for drought onset and recovery (20th percentile or $75 \%$ of normal), and number of consecutive months for triggering onset and recovery (3 months). Under a percentile-based criterion (Fig. 1a), droughts exhibited similar frequencies across the contiguous United States (CONUS). According to a percent-ofnormal criterion (Fig. 1b), however, droughts in California were more frequent than in other parts of the CONUS. Upon further investigation, a given percent-of-normal value can be associated with different probabilities of drought occurrence, and vice versa, depending on location (Fig. 2). Comparison of thresholds for values of 20th percentile and $75 \%$ of normal annual precipitation across the CONUS reveals the high susceptibility of California and the southwestern United States to drought episodes. A remarkable fact is that California is distinguished by 
Percent of Normal Corresponding to $20 \%$-ile

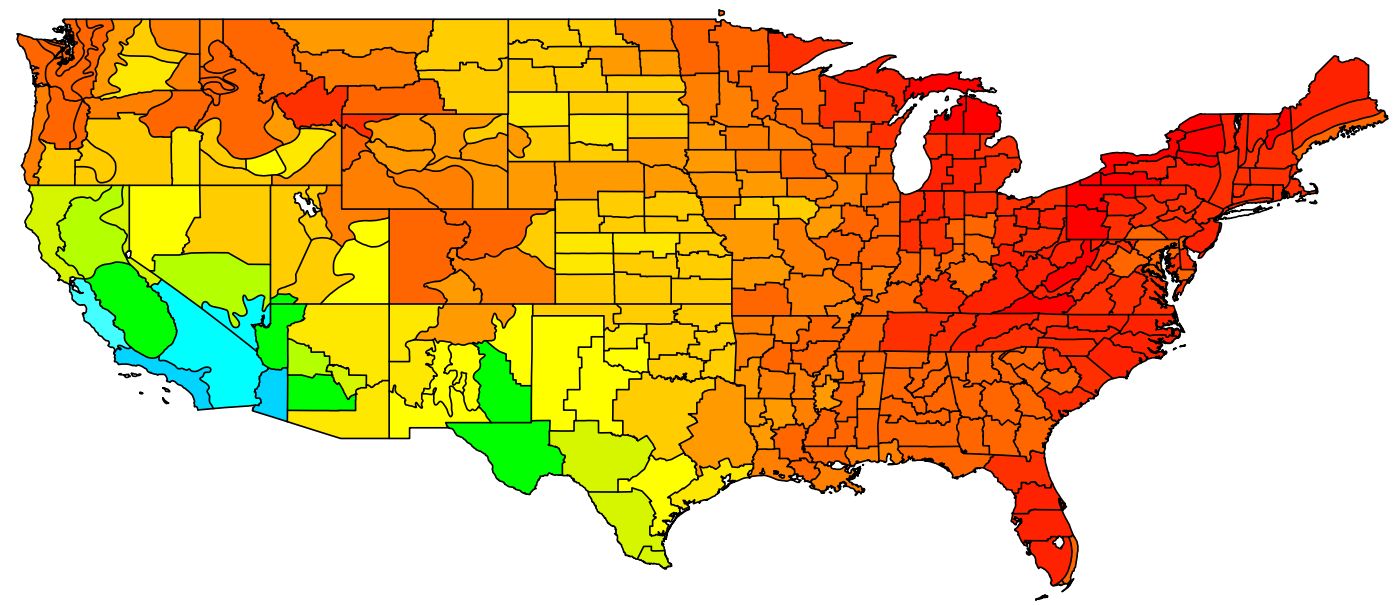

Percent of Normal

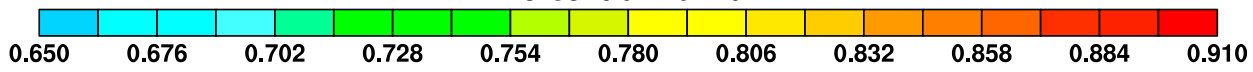

Percentile Level Corresponding to $75 \%$ of Normal
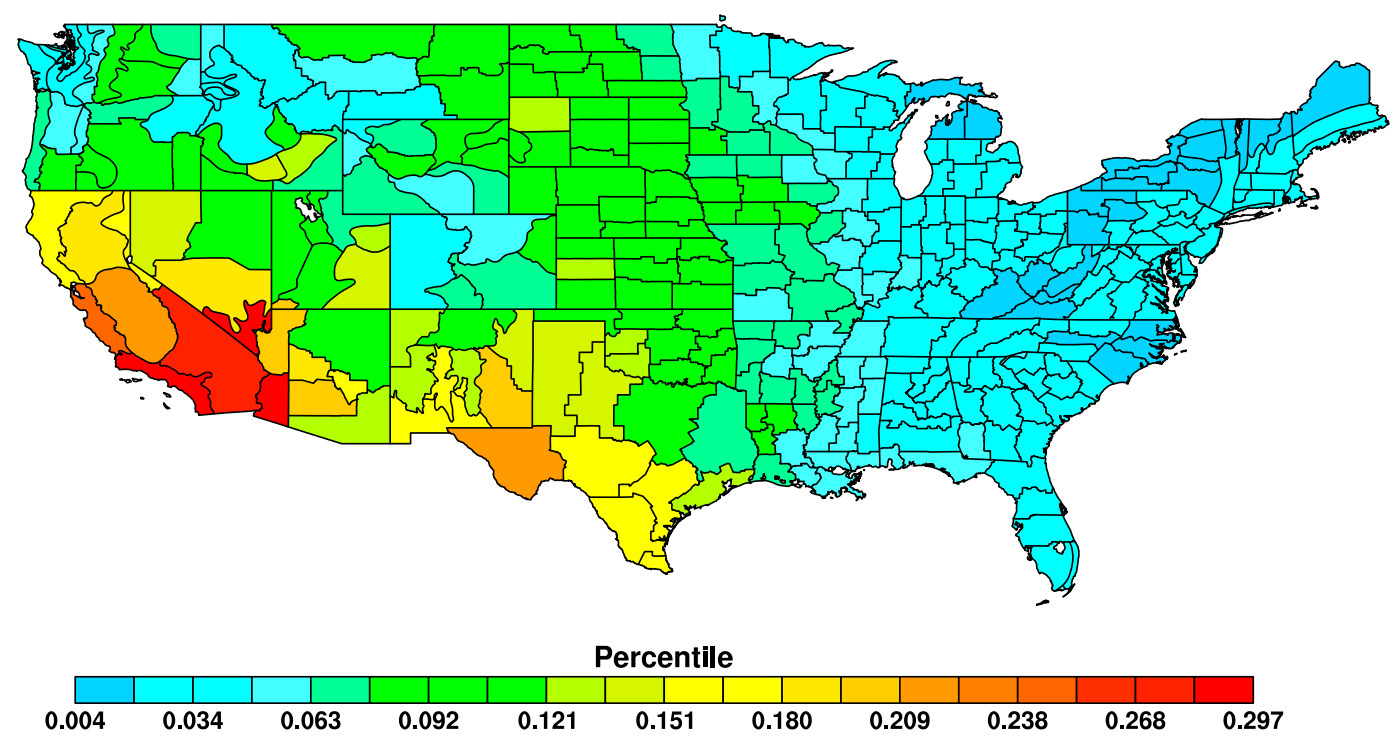

FIG. 2. (top) Percent of normal annual precipitation corresponding to the 20th percentile of annual precipitation, and (bottom) percentile level of annual precipitation corresponding to $75 \%$ of normal annual precipitation for each CD across the CONUS.

having values of 20 th percentile (in percent of normal) that are lower and values of $75 \%$ of normal precipitation (as percentiles) that are higher than elsewhere in the CONUS.

\section{Data}

This section describes the precipitation dataset used in this analysis and the indices and methods used to identify PDO and ENSO phases.

\section{a. Precipitation dataset}

We used version 2 of the National Oceanic and Atmospheric Administration (NOAA) National Climatic Data Center (NCDC) precipitation dataset reported at CD level (Vose et al. 2014). The primary source of station data for this version is the Global Historical Climatology Network-Daily dataset (Menne et al. 2012). (We downloaded this dataset from http://www1.ncdc.noaa.gov/pub/ data/cirs/climdiv/; last accessed 21 September 2014.) This 
dataset is available at a lag of about 1 month and goes back to 1895 . For further information regarding this dataset, see Vose et al. (2014).

\section{b. $P D O$}

We identified PDO warm and cool phases using NCDC's PDO index. This index is based on the NOAA Extended Reconstructed Sea Surface Temperature, version 3b (ERSST.v3b; Smith et al. 2008), dataset. (This dataset was downloaded from http://www.ncdc. noaa.gov/teleconnections/pdo/data.csv; last accessed 26 November 2014). For further details on this dataset, see online (http://www.ncdc.noaa.gov/teleconnections/ pdo/) and Mantua et al. (1997). From this index, we characterized the period of analysis into PDO cool phases (1894-1924, 1947-76, and 1999-present) and warm phases (1925-46 and 1977-98).

\section{c. ENSO}

ENSO events were identified using the average Southern Oscillation index (SOI; Ropelewski and Jones 1987) for the June-November months and following the methods of Redmond and Koch (1991) and Cayan et al. (1999). The SOI values were obtained online (http:// www.cru.uea.ac.uk/cru/data/soi/; last accessed 26 November 2014). When average June-November SOI was less than or equal to -0.50 , we identified that water year as ENSO warm phase (El Niño), and when it was equal to or greater than +0.50 , we identified that water year as ENSO cool phase (La Niña).

\section{Methods}

\section{a. Precipitation percentile calculation}

We estimated the percentile rank of each precipitation value using the climatological distribution of 18952013. Percentiles were calculated separately for each month and each water year (1 October-30 September) for each of the seven CDs (http://www.ncdc.noaa.gov/ monitoring-references/maps/us-climate-divisions.php) and for the entire state. Target precipitation values were converted to a corresponding percentile value Pctl with the following equation:

$$
\operatorname{Pctl}=\frac{\left(C_{l}+0.5 f_{i}\right)}{N} \times 100,
$$

where $C_{l}$ is the number of times that monthly precipitation values for the given month were below the target precipitation value, $f_{i}$ is the frequency with which the target precipitation value itself appears in the climatological distribution, and $N$ is the total number of years in the period of analysis.
Following results from Steinemann et al. (2015), we define a monthly drought as monthly precipitation below the 20th percentile, annual drought as water-year precipitation below the 30th percentile, and leading indicator as the monthly drought preceding or during an annual drought that has the strongest association (i.e., joint probability of occurrence) with a statewide annual drought. We use these criteria throughout, unless otherwise specified.

\section{b. Significance test}

We performed a significance test of the joint probabilities of an annual drought following a monthly drought event by using a Monte Carlo-based sampling approach. For any given month, we first determined the number (say, $N$ ) of monthly drought events during the period of analysis. We then selected the given month from $N$ randomly selected years from the observed record. We repeated this step 1000 times, resulting in 1000 samples of $N$ months. For each of the samples, we counted the number of times an annual drought event occurred in the water year consisting of that month (in the case of October-March months) or the succeeding water year (in the case of May-September months). We then estimated the 95th percentile of the distribution of the number of annual drought events. If the observed joint probability of an annual drought event with monthly drought event in a given month was above that number, we considered the joint probability value to be significant at the $95 \%$ confidence level.

\section{Results}

\section{a. Monthly contributions to annual precipitation in California}

We estimated the contribution of precipitation during each month to annual water-year precipitation for each of the CDs and for the entire state (Fig. 3) during the period of 1895-2013. In general, December, January, and February had the highest individual monthly contributions $(>14 \%$ for each month) to annual precipitation for the state and for most of the CDs. In addition, in CD4, CD5, and CD6, March also contributed $>14 \%$ to annual precipitation.

Next, we examined the coefficient of variation $(\mathrm{CV})$ of monthly precipitation (i.e., ratio of standard deviation and mean of monthly precipitation) (Fig. 3). In general, the CVs of summer months (June-September) were greater than those for the rest of the months, but the contribution of these months to annual precipitation was also low ( $<5 \%$ of annual precipitation). The CVs of winter months in California were still very high (Fig. 3); the $\mathrm{CV}$ of winter monthly precipitation was lowest in CD1 (between 0.50 and 0.70) and was highest in CD6 (between 0.80 and 0.95) and CD7 (between 0.90 and 1.0). 
(a) CDs in California

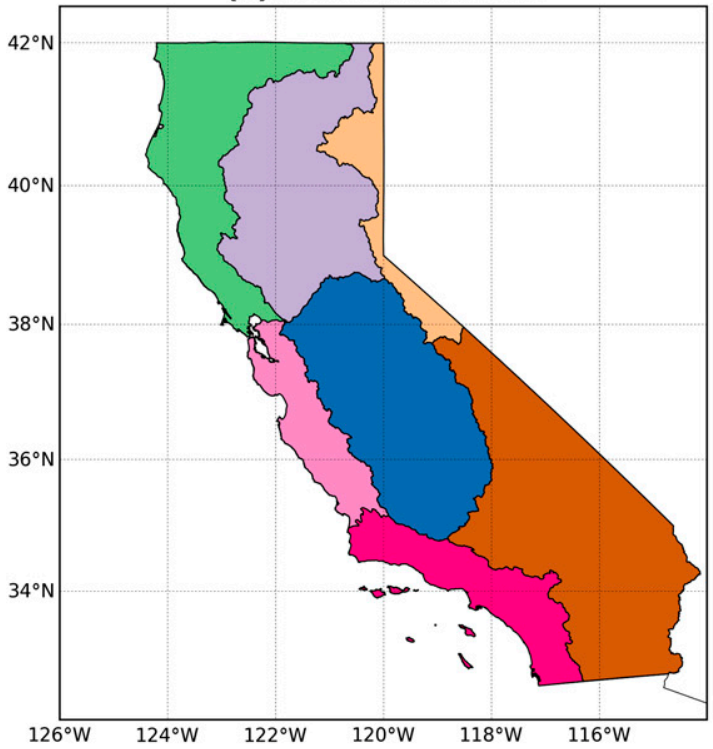

$\mathrm{CD}$ : 1-North Coast Drainage

CD: 2-Sacramento Drainage

CD: 3-Northeast Interior Basins

CD: 4-Central Coast Drainage

CD: 5-San Joaquin Drainage

CD: 6-South Coast Drainage

CD: 7-Southeast Desert Basin (b) Ratio of monthly and annual water year precipitation

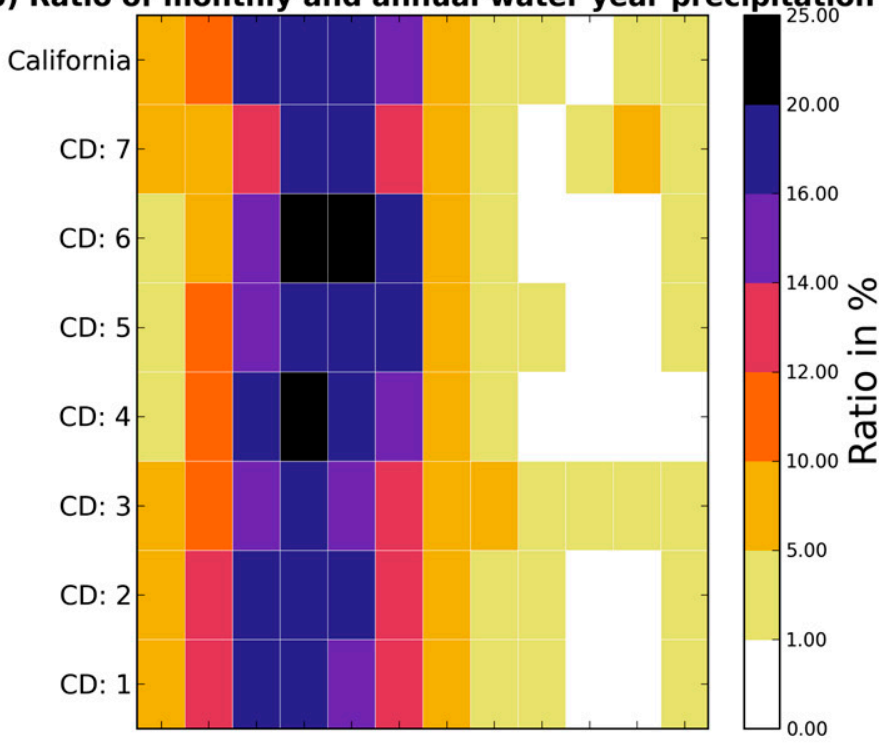

(c) Coefficient of variation of monthly precipitation

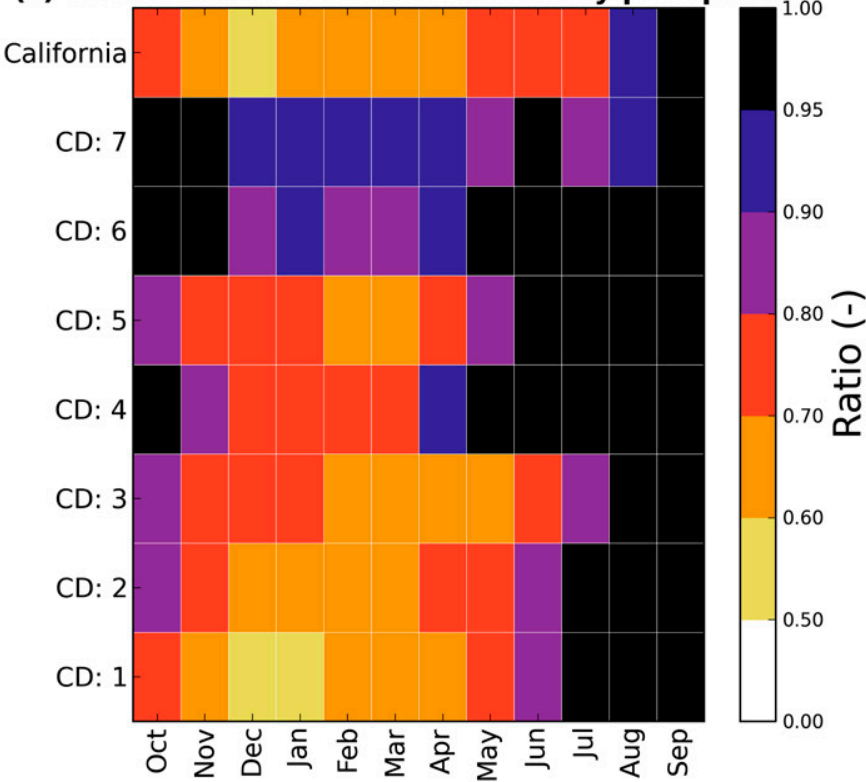

FIG. 3. (a) The CDs in California, (b) the contribution of monthly precipitation to annual water-year precipitation for the entire state and for each $\mathrm{CD}$, and (c) the $\mathrm{CV}$ of monthly precipitation.

\section{b. Association of monthly and annual drought in California}

Figure 4 shows the probability of annual precipitation being below a particular threshold (varying between the 20th and 70th percentile) in each of the CDs and the state, given monthly drought events during May-September preceding the water year and October-March of the same water year. We found that December was the leading indicator of annual drought statewide. When December was in drought (i.e., precipitation was below the 20th percentile), $56 \%$ of the time it coincided with statewide annual drought (i.e., precipitation was below the 30th percentile) and $91 \%$ of the time it was followed by statewide annual precipitation below the 50th percentile.

In comparison, when November, January, or February was in drought, then $48 \%, 43 \%$, and $46 \%$ of the time, respectively, it coincided with statewide annual drought, 
(1) North Coast Drainage

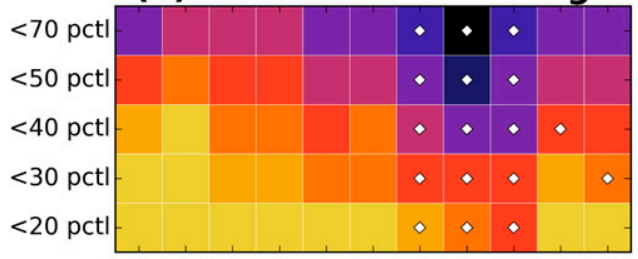

(3) Northeast Interior Basins

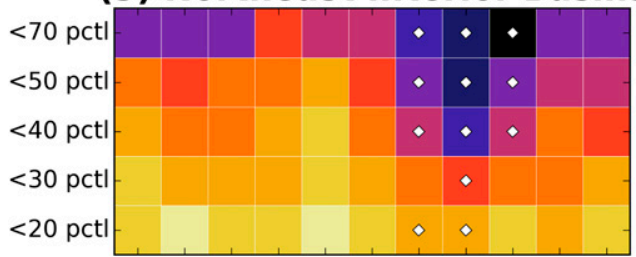

(5) San Joaquin Drainage

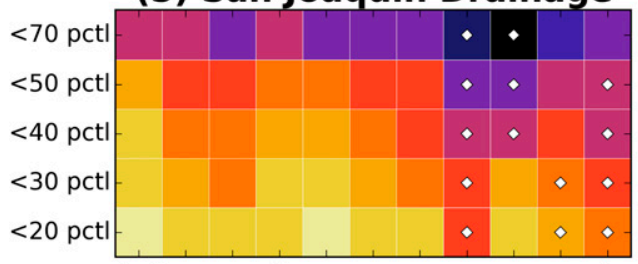

(7) Southeast Desert Basin

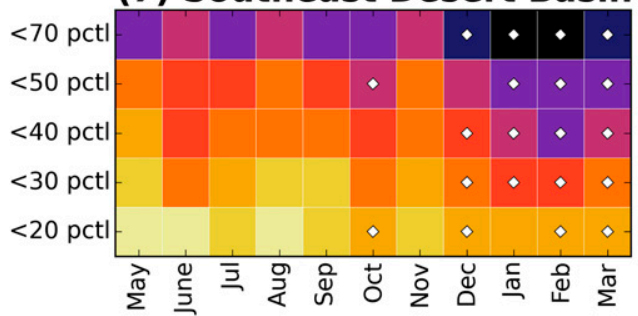

(2) Sacramento Drainage

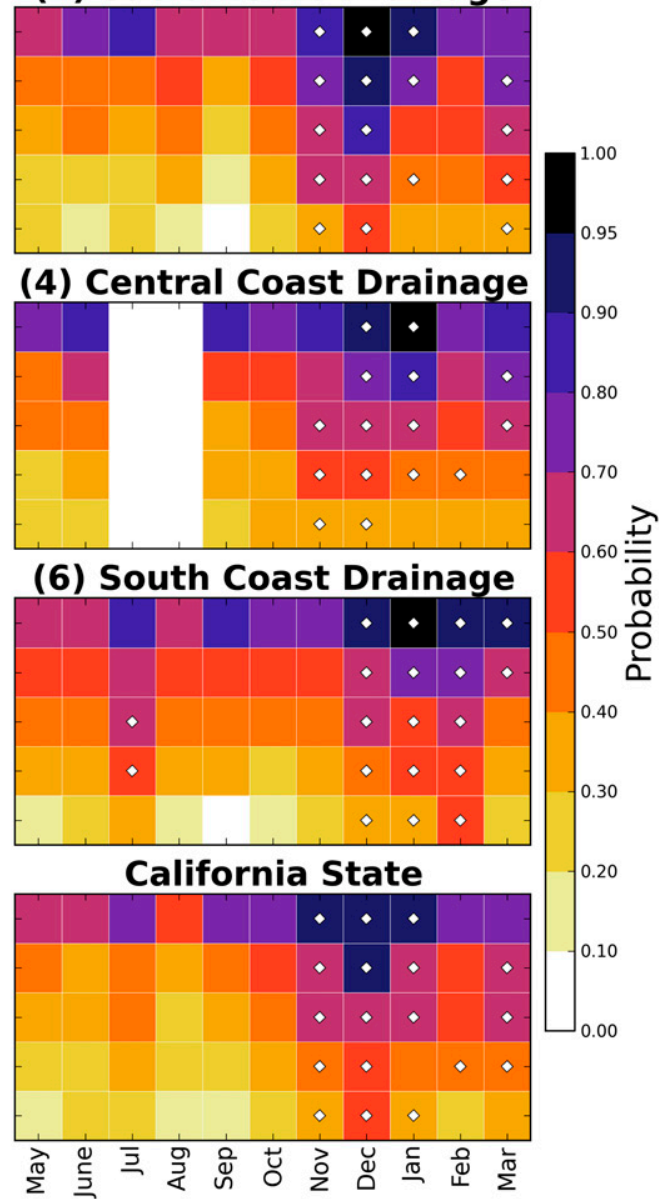

FIG. 4. Probability of annual water-year precipitation below thresholds (from $20 \%$ to $70 \%$ ) when monthly precipitation in May-September in the preceding year and October-March in the same water year was below $20 \%$. (The white diamonds indicates significance at the $95 \%$ confidence level.)

and $70 \%, 70 \%$, and $58 \%$ of the time, respectively, it was followed by statewide annual precipitation below the 50th percentile. The highest probability of annual drought associated with December drought, among the CDs, was $65 \%$ for CD2. In all cases, the percentage of time that December drought was associated with annual drought was statistically significant at the $95 \%$ confidence level.

We also examined the joint probability of December drought with annual drought for the CDs in the rest of the CONUS (Fig. S1 in the online supplemental material) and found that California is one of the few states for which all CDs show strong association (joint probability $>48 \%$ ) of December drought with annual drought. We also found that CD2 in California was among only 5 CDs across the CONUS (of a total of 344) for which the joint probability of December drought with annual drought was greater than $65 \%$.

\section{c. Joint probability of droughts in winter months}

We next examined the association of drought events among winter months. Figure 5 shows the joint probability of a winter month (November-March; $y$ axis) being in drought (monthly precipitation below the 30th percentile, in this case) with another winter month (NovemberMarch; $x$ axis) being in substantial drought (monthly precipitation below the 20th percentile). Statewide joint probabilities of December drought (monthly precipitation below 20th percentile) and other winter months (November-March) being in drought (monthly precipitation below 30th percentile, in this case) were between $30 \%$ and $48 \%$ : for $48 \%$ of the years when December was in drought, November was also in drought, and December drought also had a relatively high joint probability with January (30\%) and February (35\%), both of which have high contribution to annual 
(1) North Coast Drainage

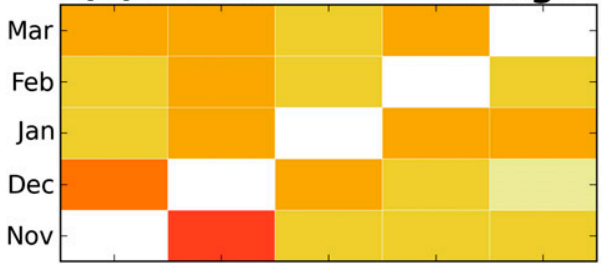

(3) Northeast Interior Basins

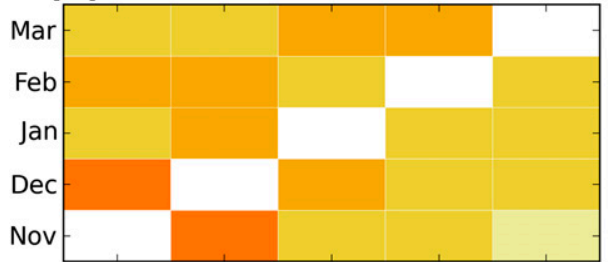

(5) San Joaquin Drainage

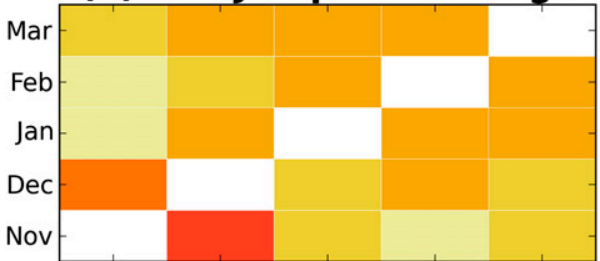

(7) Southeast Desert Basin

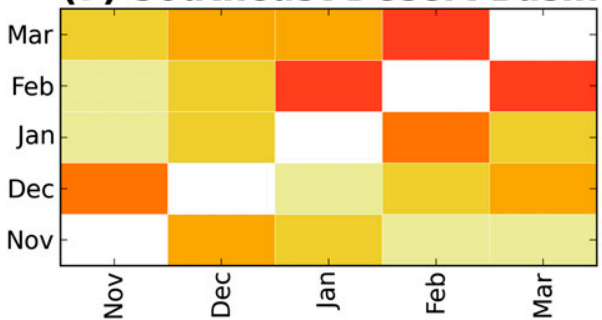

(2) Sacramento Drainage

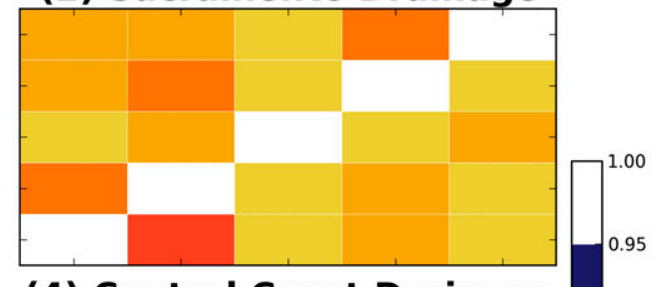

(4) Central Coast Drainage

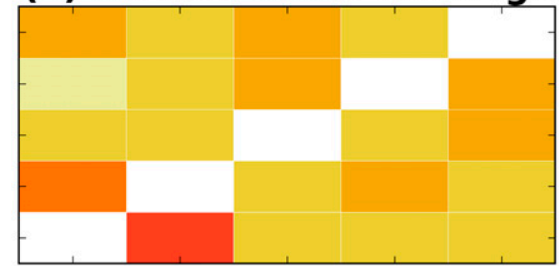

(6) South Coast Drainage

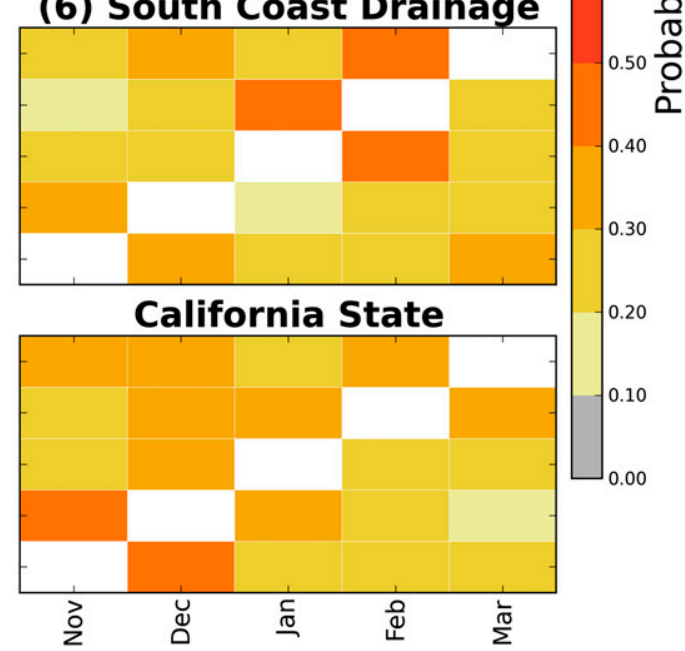

FIG. 5. Joint probability of a winter month ( $y$ axis) being in drought (monthly precipitation $<30 \%$ ) with another winter month ( $x$ axis) being in drought (monthly precipitation $<20 \%$ ).

precipitation (Fig. 3). November, January, and February had between $22 \%$ and $43 \%$, between $26 \%$ and $35 \%$, and between $21 \%$ and $33 \%$, respectively, joint probability of being in drought with the rest of the winter months.

\section{d. Variability of annual drought frequency and leading-indicator months with climate phases}

We examined how annual drought in California and leading-indicator month varied by different climate phases during the period 1895-2013 (Fig. 6). This analysis was conducted by using the subsets of years from the analysis period that belonged to a certain climate phase. Climate phases considered in this analysis were PDO warm and cool phases and ENSO warm (El Niño) and cool (La Niña) phases. Sample sizes for each of the climate phases (in years) were 44 (PDO warm phases), 74 (PDO cool phases), 37 (ENSO warm phases), and 27 (ENSO cool phases).

We found no clear association of statewide annual drought events with a given climate phase. At the $\mathrm{CD}$ level, during PDO cool phases and ENSO cool phases the frequency of annual drought was highest for CD6 and CD7 (36\% and 35\%, respectively, for PDO cool phases and $33 \%$ and $41 \%$, respectively, for ENSO cool phases) among all CDs. During PDO warm phases the frequency of annual drought was highest for CD1 (41\%), and during ENSO warm phases the frequency was highest for $\mathrm{CD} 2$ and $\mathrm{CD} 3(35 \%$ and $38 \%$, respectively) among all CDs.

During PDO cool phases, February was most often associated with annual drought in CD6 (44\% of the time) and CD7 (50\% of the time). During ENSO cool phases, January was most often associated with annual drought in CD6 (67\% of the time) and March was most often associated with annual drought in CD7 (55\% of the time). In PDO warm phases, November was most often associated with annual drought in CD1 (56\% of the time). In ENSO warm phases, February was most often associated with annual 


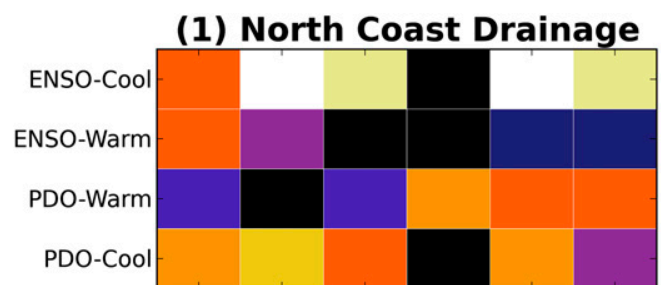

(3) Northeast Interior Basins

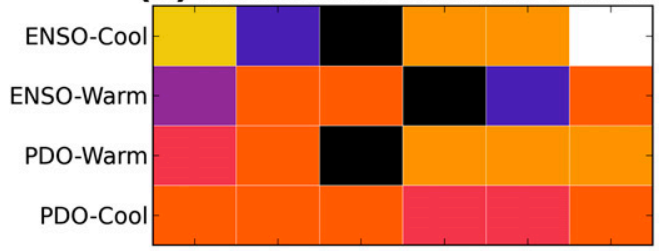

(5) San Joaquin Drainage

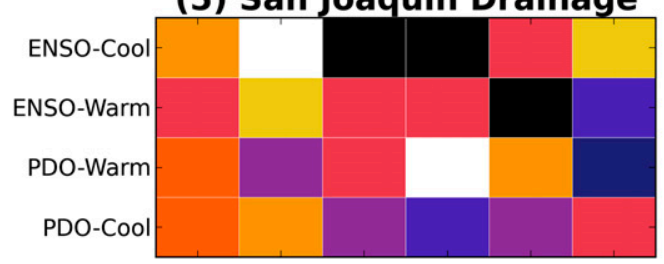

(7) Southeast Desert Basin

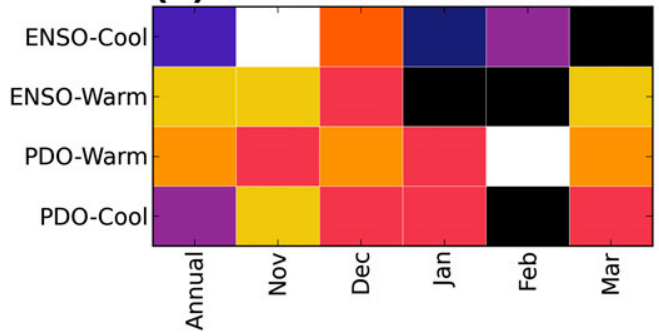

(2) Sacramento Drainage

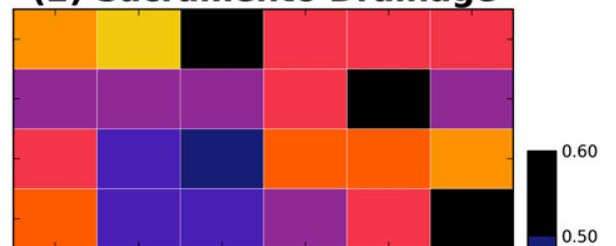

(4) Central Coast Drainage

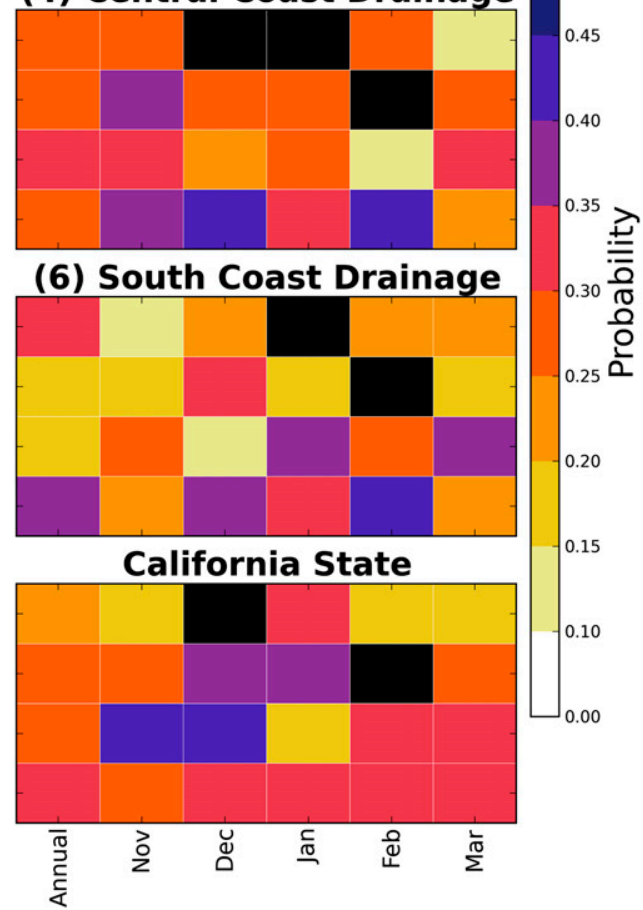

FIG. 6. Probability of annual drought (precipitation below the 30th percentile) during a given climate phase with a given winter month in drought (precipitation below the 20th percentile) during that climate phase.

drought in CD2 (54\% of the time) and January was most often associated with annual drought in CD3 (50\% of the time).

\section{Concluding remarks}

We investigated historical relationships between monthly and annual precipitation in California, with a focus on drought conditions. California is distinguished from the rest of the CONUS by having the greatest yearto-year variability in precipitation. In the context of drought, this high variability in California translates to its having values of 20th percentile (in percent of normal) that are lower than those elsewhere in the CONUS and values of $75 \%$ of normal precipitation (as percentiles) that are higher than those elsewhere in the CONUS.

Considering the occurrence of monthly and annual drought to be $<20$ th-percentile monthly precipitation and $<30$ th-percentile water-year precipitation, respectively, our primary findings are as follows: 1) During
1895-2013, December was the leading indicator of annual drought. Of course, the monthly makeup of annual drought varies across annual drought cases, but, over the period of record, $56 \%$ of the time in which December was in drought it was followed by statewide annual drought and $91 \%$ of the time it was followed by statewide annual precipitation below 50\%. 2) December drought was also most often associated with drought in other winter months (joint probability $>30 \%$ ). 3) In PDO cool phases, February was most often associated with annual drought in CD6 (44\% of the time) and CD7 (50\% of the time). In ENSO cool phases, January was most often associated with annual drought in CD6 (67\% of the time) and March was most often associated with annual drought in CD7 (55\% of the time). 4) In PDO warm phases, November was most often associated with annual drought in CD1 (56\% of the time). In ENSO warm phases, February was most often associated with annual drought in CD2 (54\% of the time) and January was most often associated with annual drought in CD3 (50\% of the time). 
The approach used in this study is intended to be understood easily by stakeholders, is temporally and spatially consistent, and can be adjusted to accommodate different drought criteria. We recognize that the current study does have some limitations. It has defined drought specifically and narrowly (on the basis of precipitation only), and other criteria (including different hydrological variables and different percentile thresholds) could be explored. It also did not consider the prior water year, which can influence the likelihood of the development or persistence of drought in subsequent water years. It also did not investigate the dynamical causes of why a certain month was often a leading indicator of annual drought in California and why some months had higher joint probabilities of drought than others did, which are questions to explore in future work. Nonetheless, this study reveals important relationships between monthly precipitation and annual drought in California and helps to address stakeholder questions about drought development during a water year.

Acknowledgments. This study received support through the California-Nevada Applications Program (NA11OAR4310150) and other National Oceanic and Atmospheric Administration Grants (NA13OAR4310172 and NA15OAR4320071), the National Integrated Drought Information System, and the Southwest Climate Science Center.

\section{REFERENCES}

California Department of Water Resources, 2014: Public update for drought response. Groundwater basins with potential water shortages, gaps in groundwater monitoring, monitoring of land subsidence, and agricultural land fallowing. State of California Natural Resources Agency Rep., 52 pp. [Available online at http://www.water.ca.gov/waterconditions/docs/DWR PublicUpdateforDroughtResponse_GroundwaterBasins.pdf.]

Cayan, D. R., and J. O. Roads, 1984: Local relationships between United States West Coast precipitation and monthly mean circulation parameters. Mon. Wea. Rev., 112, 1276-1282, doi:10.1175/1520-0493(1984)112<1276:LRBUSW > 2.0.CO;2.

—, M. D. Dettinger, H. F. Diaz, and N. E. Graham, 1998: Decadal variability of precipitation over western North America. J. Climate, 11, 3148-3166, doi:10.1175/1520-0442(1998)011<3148: DVOPOW $>2.0 . \mathrm{CO} ; 2$.

— , K. T. Redmond, and L. G. Riddle, 1999: ENSO and hydrologic extremes in the western United States. J. Climate, 12, 2881-2893, doi:10.1175/1520-0442(1999)012<2881:EAHEIT>2.0.CO;2.
Dettinger, M. D., F. M. Ralph, T. Das, P. J. Neiman, and D. R. Cayan, 2011: Atmospheric rivers, floods and the water resources of California. Water, 3, 445-478, doi:10.3390/w3020445.

Fierro, A. O., 2014: Relationships between California rainfall variability and large-scale climate drivers. Int. J. Climatol., 34, 3626-3640, doi:10.1002/joc.4112.

Griffin, D., and K. J. Anchukaitis, 2014: How unusual is the 20122014 California drought? Geophys. Res. Lett., 41, 9017-9023, doi:10.1002/2014GL062433.

Haston, L., and J. Michaelsen, 1994: Long-term central coastal California precipitation variability and relationships to El Niño-Southern Oscillation. J. Climate, 7, 1373-1387, doi:10.1175/ 1520-0442(1994)007<1373:LTCCCP>2.0.CO;2.

Jones, C., 2000: Occurrence of extreme precipitation events in California and relationships with the Madden-Julian oscillation. J. Climate, 13, 3576-3587, doi:10.1175/1520-0442(2000)013<3576: OOEPEI $>2.0 . \mathrm{CO} ; 2$.

Mantua, N. J., S. R. Hare, Y. Zhang, J. M. Wallace, and R. C. Francis, 1997: A Pacific interdecadal climate oscillation with impacts on salmon production. Bull. Amer. Meteor. Soc., 78, 10691079, doi:10.1175/1520-0477(1997)078<1069:APICOW>2.0.CO;2.

McAfee, S. A., 2014: Consistency and the lack thereof in Pacific decadal oscillation impacts on North American winter climate. J. Climate, 27, 7410-7431, doi:10.1175/JCLI-D-14-00143.1.

Menne, M. J., I. Durre, R. S. Vose, B. E. Gleason, and T. G. Houston, 2012: An overview of the Global Historical Climatology Network-Daily database. J. Atmos. Oceanic Technol., 29, 897-910, doi:10.1175/JTECH-D-11-00103.1.

Mo, K. C., and R. W. Higgins, 1998: Tropical convection and precipitation regimes in the western United States. J. Climate, 11, 2404-2423, doi:10.1175/1520-0442(1998)011<2404: TCAPRI $>2.0 . \mathrm{CO} ; 2$.

Redmond, K. T., and R. W. Koch, 1991: Surface climate and streamflow variability in the western United States and their relationship to large-scale circulation indices. Water Resour. Res., 27, 2381-2399, doi:10.1029/91WR00690.

Ropelewski, C. F., and P. D. Jones, 1987: An extension of the TahitiDarwin Southern Oscillation index. Mon. Wea. Rev., 115, 21612165, doi:10.1175/1520-0493(1987)115<2161:AEOTTS>2.0.CO;2.

Smith, T. M., R. W. Reynolds, T. C. Peterson, and J. Lawrimore, 2008: Improvements to NOAA's Historical Merged LandOcean Surface Temperature analysis (1880-2006). J. Climate, 21, 2283-2296, doi:10.1175/2007JCLI2100.1.

Steinemann, A., S. F. Iacobellis, and D. R. Cayan, 2015: Developing and evaluating drought indicators for decision-making. J. Hydrometeor., 16, 1793-1803, doi:10.1175/JHM-D-14-0234.1.

Vose, R. S., and Coauthors, 2014: Improved historical temperature and precipitation time series for U.S. climate divisions. J. Appl. Meteor. Climatol., 53, 1232-1251, doi:10.1175/JAMC-D-13-0248.1.

Woolhiser, D. A., T. O. Keefer, and K. T. Redmond, 1993: Southern Oscillation effects on daily precipitation in the southwestern United States. Water Resour. Res., 29, 1287-1295, doi:10.1029/ 92WR02536. 